\title{
СРАВНИТЕЛЬНОЕ ИССЛЕДОВАНИЕ ФАРМАКОКИНЕТИКИ И ФАРМАКОДИНАМИКИ БИОСИМИЛЯРА ПРЕПАРАТА ИНСУЛИН АСПАРТ
}

\author{
'Майоров А.Ю., ${ }^{2}$ Каронова Т.Л., ${ }^{1}$ Кокшарова Е.О., ${ }^{3}$ Доротенко А.Р. \\ 'ФГБУ «НМИЦ эндокринологии» Минздрава России, Москва \\ ${ }^{2}$ ФГБУ «Национальный медицинский исследовательский центр имени В.А. Алмазова» Минздрава России, \\ Санкт-Петербург \\ ${ }^{3} \mathrm{OOO}$ «ЕРОФАРМ», Санкт-Петербург
}

Программа разработки биосимиляров аналогов инсулинов представляет собой сложный, многостадийный, строго регламентированный процесс, одним из ключевых этапов которого является изучение фармакокинетических (ФК) и фармакодинамических (ФД) свойств тестируемого препарата в условиях клинического исследования.

ЦЕЛЬ: оценка сопоставимости ФК/ФД профилей оригинального препарата инсулина аспарт и воспроизведенного биосимиляра отечественного производства в форме раствора для внутривенного и подкожного введения, с использованием метода гиперинсулинемического эугликемического клэмпа (ГЭК) у здоровых добровольцев.

МАТЕРИАЛЫ И МЕТОДЫ: исследование было проведено у 26 здоровых добровольцев мужского пола в возрасте от 18 до 45 лет. В качестве дизайна исследования выбрано двойное слепое, рандомизированное, перекрестное исследование сравнительной фармакокинетики и фармакодинамики исследуемых препаратов. В условиях проведения ГЭК, после подкожного введения исследуемого инсулина субъекту, осуществлялся регулярный мониторинг уровня глюкозы крови. При ее снижении начинали управляемую внутривенную инфузию раствора глюкозы. Скорость инфузии глюкозы (GIR) регулировали таким образом, чтобы поддерживать уровень глюкозы крови на изначально обозначенном физиологическом уровне. Препараты инсулина вводили в дозе 0,3 ЕД/кг однократно подкожно в область передней брюшной стенки живота. В течение исследования проводили регулярный забор крови. В образцах плазмы крови определяли концентрацию инсулина аспарт валидизированным методом с помощью иммуноферментного анализа. В качестве ФК показателей производили оценку площади под кривой концентрации инулинавремя (AUC ins.o- $_{\text {. }}$ ) и максимальной концентрации инсулина $\left(C_{\text {ins.max }}\right)$. На основании измерения показателя GIR были построены ФД профили исследуемых препаратов, в которых оценивали площадь под кривой скорости инфузии глюкозы-время (AUC $\left.\mathrm{GIR--}_{\mathrm{t}}\right)$ и максимальной скорости инфузии глюкозы $\left(\mathrm{GIR}_{\text {max }}\right)$.

PEЗУЛЬTATЫ: в ходе проведения настоящего клинического исследования были оценены 90\% довери-

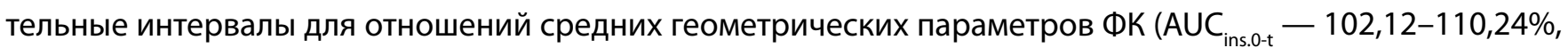

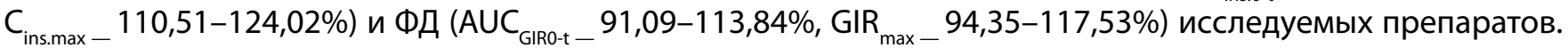
Исходя из полученных данных установлено, что доверительные интервалы исследуемых препаратов не выходили за установленные допустимые границы 80-125\%. Также, в исследовании была оценена межиндивидуальная вариабельность ФК и ФД показателей. Для AUC ins.0-т $_{\text {он }}$ онаставила 21.77 и 27.86\%, для $\mathrm{C}_{\text {ins.max }}-30.16$ и 29.60\% для биосимиляра и оригинального препарата соответственно. Сопоставимые данные были получены в отношении межиндивидуальной вариабельности ФД показателей: для AUC GlRo-t $_{-}$ 28.59 и $31.02 \%$, для $\mathrm{GIR}_{\max }-30.6$ и 31.55\% для биосимиляра и оригинального препарата соответственно.

ВЫВоды: таким образом, по результатам проведенного клэмп-исследования была доказана полная биосимилярность воспроизведенного аналога инсулина аспарт оригинальному препарату с отсутствием межиндивидуальной вариабельности воспроизведенного аналога по сравнению с оригинальным препаратом. 